\title{
Unusual cause of gastric outlet obstruction: giant gastric trichobezoar: a case report Ibrahim Yetim ${ }^{1}$, Orhan Veli Ozkan*1, Ersan Semerci ${ }^{1}$ and Recep Abanoz ${ }^{2}$
}

\author{
Address: ${ }^{1}$ Mustafa Kemal University, Faculty of Medicine, Department of General Surgery, Antakya/Hatay, Turkey and ${ }^{2}$ Bafra State Hospital, Bafra/ \\ Samsun, Turkey \\ Email: Ibrahim Yetim - yetim54@gmail.com; Orhan Veli Ozkan* - veliorhan@hotmail.com; Ersan Semerci - ersemerci@yahoo.com; \\ Recep Abanoz - drrecepabanoz@gmail.com \\ * Corresponding author
}

Published: 16 December 2008

Cases Journal 2008, I:399 doi:10.1186/1757-1626-1-399

This article is available from: http://www.casesjournal.com/content///I/399

(C) 2008 Yetim et al; licensee BioMed Central Ltd.

This is an Open Access article distributed under the terms of the Creative Commons Attribution License (http://creativecommons.org/licenses/by/2.0), which permits unrestricted use, distribution, and reproduction in any medium, provided the original work is properly cited.
Received: 12 November 2008

Accepted: 16 December 2008

\begin{abstract}
Background: Trichobezoars are caused by hair ingestion. The usual presentation of a trichobezoar is with early satiety and malnutrition. Obstructive symptoms and manifestations of gastric outlet obstruction may occur. The diagnosis may be suspected in young females with malnutrition, who have a history of trichophagia.
\end{abstract}

Case presentation: We report a case of 12-year-old female admitted to the emergency room for abdominal pain. On physical examination, she was cachectic and an epigastric mass was palpated. An exploratory laparotomy was conducted. A giant trichobezoar was palpated in the stomach and was removed through an anterior gastrostomy.

Conclusion: There were no complications postoperatively and the patient was referred to a psychiatrist.

\section{Background}

Bezoars are incompletely digested food or fibrous materials that may cause intestinal obstruction over the time. Common clinical symptoms include abdominal pain, nausea, vomiting, weight loss [1]. Trichobezoars are seen in case of large amount of hair ingestion. Trichobezoars are more common in paediatric age than adults with up to $90 \%$ occurring in girls [2]. In this report, we describe a 12year-old girl with obstructing trichobezoar of stomach and duodenum.

\section{Case report}

A 12 year old girl was admitted to our emergency department with 5 days history of abdominal pain and non-bilious vomiting. On physical examination, patient was cachectic and an epigastric mass was palpated. Biochemical results were normal except mild anaemia. X-ray depicted that stomach was dilated with no air-fluid level. Ultrasonography (USG) revealed hyperechoic mass on the epigastric region. On the computed tomography (CT) appearance, there was a heterogenous lesion from stomach to horizontal duodenal part that causes distation with circumcised air trapping (Figure 1). Patient had history of trichophagia for a long time. Patient underwent laparotomy. Upper midline incision was performed. A giant trichobezoar was removed through an anterior gastrostomy. This mass extended to proximal part of duodenum. The mass weighed $125 \mathrm{~g}$ and measured $8.5 \times 22 \mathrm{~cm}$ (figure 2). There was no complication postoperatively. Patient was discharged a week later. 


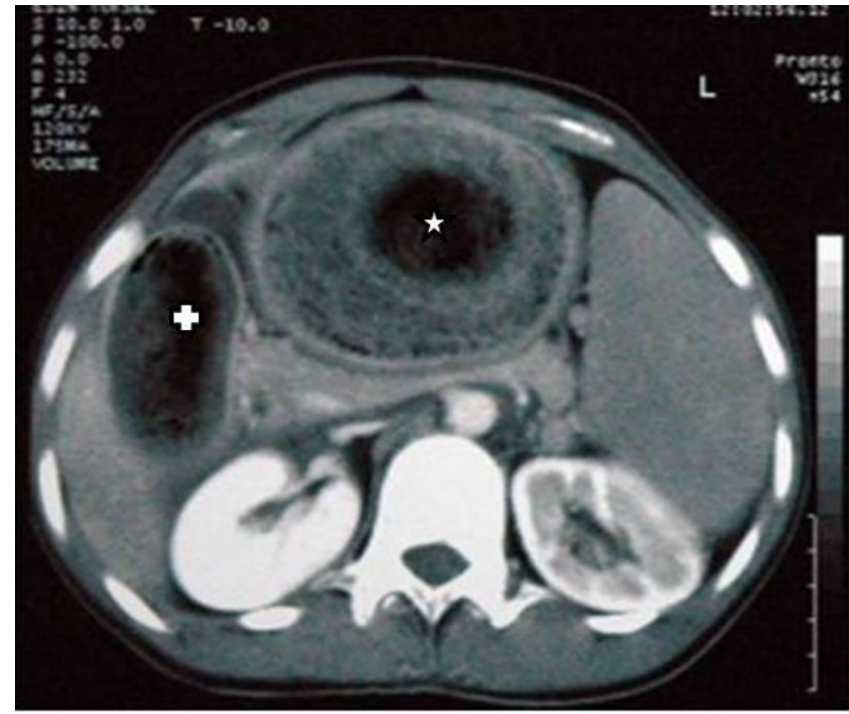

Figure I

Computed tomogram of the Abdomen. Trichobezoar seen on Stomach (㧒) and duodenum (\$)

\section{Discussion}

The term bezoar was derived from the Persian word 'panzeh' meaning 'antidote' [3]. In ancient times, bezoars were considered as a protection against poisoning. They are divided into three categories according to components; phytobezoars (plant material), trichobezoars (hair) and lactobezoars (milk) [4]. Phytobezoars are generally found in patients with history of gastric surgery. Lactobezoars are exclusively found in infants. Prematurity and concen-

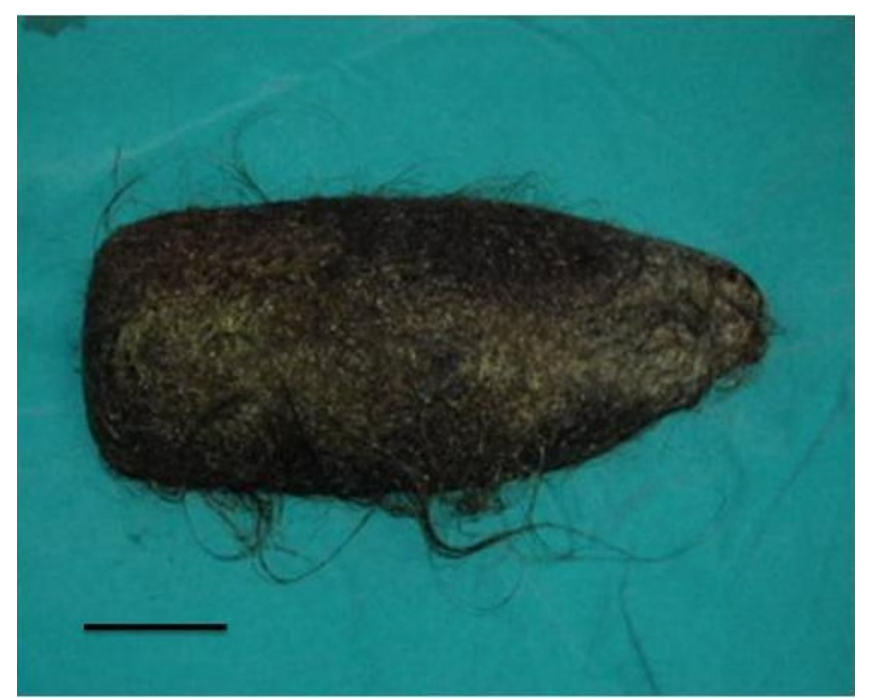

Figure 2

Trichobezoar extracted from stomach with an approximate length $22 \mathrm{~cm}$ (Black bar is shown approximately $5 \mathrm{~cm}$ length). trated formulas are leading causes of lactobezoars. Trichobezoars are caused by ingestion of high amount of hair over many years. They are formed typically in stomach and they may enlarge leading to gastric outlet obstruction $[5,6]$ The cause of hair ingestion may be associated with mental retardation, pica or trichotillomania which is a behavioural disturbance characterized by the compulsive urge to pull one's hair and eat it. Up to $90 \%$ of all trichobezoars occur in girls younger than 20 years old [2]. Males are rarely affected. Trichobezoar have a special type called 'Rapunzel Syndrome'. In that syndrome gastric trichobezoars could have a long tail that can extent to ileoceal valve $[7,8]$.

Common presenting symptoms are abdominal pain, nausea, vomiting, weight loss, malnutrition, hematemesis, diarrhoea or constipation. On physical examination epigastric mass may be palpated. Alopecia may also be present due to trichotillomania.

USG and CT imaging features are helpful in diagnosis. On the USG, bright echogenic band and shadow over the left upper quadrant may exist. CT demonstrates heterogenous, mottled intraluminal mass with low attenuation and air trapping [9].

Phytobezoars may be digested enzimatically but trichobezoars are generally resistant to that treatment. Small gastric bezoars can be removed endoscopically. Large gastric trichobezoars can be removed either endoscopically or by laparotomy. In our case, a giant bezoar had caused duodenal obstruction. Small intestinal obstruction is rare but small intestine examination is important for ensuring about any other mass remnant.

Since recurrences could occur, the patient must be directed to psychiatric follow-up after the operation.

\section{Consent}

Written informed consent was obtained from the patient for publication of this case report and accompanying images. A copy of the written consent is available for review by the Editor- in - Chief of this Journal.

\section{Competing interests}

The authors declare that they have no competing interests.

\section{Authors' contributions}

IY and RA analysed and interpreted the patient data. OVO and ES performed the literature review, and was a major contributor in writing the manuscript. OVO and IY performed the final editing of the manuscript. All authors read and approved the final manuscript. 


\section{References}

I. Hoover K, Piotrowski J, St Pierre K, Katz A, Goldstein AM: Simultaneous gastric and small intestinal trichobezoars - a hairy problem. J Pediatr Surg 2006, 4I: I495-I 497.

2. Lynch KA, Feola PG, Guenther E: Gastric trichobezoar: An important cause of abdominal pain presenting to the pediatric emergency department. Pediatr Emr Care 2003, 19(5):343-347.

3. DuBose TM, Southgate WM, Hill JG: Lactobezoars: A patient series and literature review. Clin Pediatr 200I, 40:603-606.

4. Ratan SK, Grover SB: Giant rectosigmoid stone bezoar in a child. Clin Pediatr 2000, 39:500-502.

5. Kaplan M, Ozeri Y, Agranat A, Brisk R, Eylath U: Antacid bezoar in a premature infant. Am J Perinatol 1995, I 2:98-99.

6. Tsou VM, Bishop PR, Nowicki MJ: Colonic sunflower seed bezoar. Pediatrics 1997, 99:896-897.

7. Kleiner O, Finaly R, Cohen Z: Giant gastric trichobezoar presenting as abdominal mass in a child. Acta Pediatr 2002, 91:1273-1274.

8. West WM, Duncan ND: CT appearances of the Rapunzel syndrome: An unusual form of bezoar and gastrointestinal obstruction. Pediatr Radiol 1998, 28:315-316.

9. Newman B, Girdany BR: Gastric trichobezoars - sonographic and computed tomographic appearance. Pediatr Radiol 1990 , 20:526-527.

Publish with Biomed Central and every scientist can read your work free of charge

"BioMed Central will be the most significant development for disseminating the results of biomedical research in our lifetime. "

Sir Paul Nurse, Cancer Research UK

Your research papers will be:

- available free of charge to the entire biomedical community

- peer reviewed and published immediately upon acceptance

- cited in PubMed and archived on PubMed Central

- yours - you keep the copyright 